\title{
Psicanálise: Desconcertos sobre o que herdamos, o que fazemos e o que transmitimos ${ }^{1}$
}

\author{
José Antonio Pavan²
}

Antes de mais nada, meus agradecimentos à Diretoria Científica da SBPSP pelo honroso convite para participar como comentador nesta Oficina.

Considerando a solicitação da Coordenação da Comissão Organizadora deste evento para que o comentador escolhesse um ponto de um dos trabalhos apresentados na plenária, e aos limites indicados para o tamanho do texto, gostaria de me ater ao final do artigo do colega Márcio F. Giovannetti, onde descreve a experiência clínica com seu paciente, estando o mesmo, em sintonia com a temática proposta:

"Afonso vivia, por um lado, capturado em um mundo melancólico e, por outro, capturado em um mundo corporativo financeiro. Por um lado, a voz imperativa de sua mãe, por outro, as regras inescapáveis ditadas pelo banco. Assim, impedido de ser um "formador de mundo", vivia na pobreza de um passado congelado e de um presente acelerado. Seu Eu apequenado era quase que uma extensão do grupo familiar ou do grupo de inserção profissional. Um Eu em condomínio, poder-se-ia dizer. A evolução de sua análise que ainda está em andamento tem sido na direção de uma construção de um Eu próprio, sua casa, sendo capaz de se sentir seguro num espaço existencial próprio."

\footnotetext{
${ }^{1}$ Este trabalho foi apresentado em oficina sobre as plenárias no I Simpósio Bienal "O mesmo, o outro: Psicanálise em movimento" eixo "O analista desconcertado: mal estar e cínica” da Sociedade Brasileira de Psicanálise de São Paulo.

${ }^{2}$ Membro Efetivo da SBPSP e do Núcleo de Psicanálise de Marília e Região.
} 
“Tarefa análoga se impõe a todos nós analistas praticantes neste início de um novo milênio. Nem nos deixarmos aprisionar no espaço conceitual por nós herdado, nem nos deixarmos capturar ou absorver passivamente pela aceleração constante do mundo contemporâneo, a infosfera, como a batizou Floridi. Nem aprisionar a fala viva de nossos pacientes no mundo conceitual por nós herdado, nem nos deixarmos paralisar pelo desconcerto que ela fatalmente nos traz. Só assim estaremos inseridos na melhor das tradições, a de preservar ofogo e jamais cultuar as cinzas."

Se o tema que estamos tratando é "O Analista Desconcertado: Mal-estar e Clínica", acredito que o mesmo suscita muitas indagações (interrogações) e questionamentos, mais do que respostas inquestionáveis.

Podemos iniciar pensando como nos tornamos os analistas de hoje, sendo analisados pelos de ontem, muitos estando entre nós, e certamente, não sendo mais os mesmos? Minha geração, foi formada em psicanálise por analistas da tradição freudiana, mas com uma herança kleiniana muito forte, e tendo Bion convivendo entre nós, com toda sua carismática influência. No meu caso particular, iniciei o trajeto da formação psicanalítica enfrentado o luto na nossa sociedade pela sua recente perda. Temos aqui o aspecto Institucional com todo seu peso determinante do destino do futuro psicanalista, e de promover desconcertos na ordem estabelecida, onde a formação analítica se desenvolve em uma assimetria com uma "formatação", preservando a tradição, sem traição aos ideais psicanalíticos em constante evolução.

Assim, entramos neste novo milênio, com toda tradição de nossa formação e toda demanda social da contemporaneidade, caracterizada pela hipertrofia informacional e pela solicitação de eficiência e imediatismo, exigida por uma conformação à Tecnologia em vertiginosa transformação.

Historicamente, em sua descoberta/criação e seus fundamentos a Psicanálise é eminentemente clínica, dela surgindo e a ela se dedicando. Trata de pessoas, em suas 
particularidades, mas que vivem em sociedade, o que determina conflitos, tanto intrapsíquicos quanto interpessoais.

O que caracteriza a contemporaneidade e qual o papel da Psicanálise neste contexto? Como a nova ordem vai determinar as relações sociais? Que consequências há para nossa prática?

O tema do desconcerto do analista, mal-estar e clínica, instiga a pensarmos seus conteúdos. Não é possível, me parece, o desconcerto onde não haja previamente algum grau de concerto (diferentemente de "consertos"). O termo concerto faz lembrar mais de sintonias, sincronias, ou, pensando em música, sinfonias. O desconcerto é uma ruptura deste estado, manifestandose clinicamente como angústias, inibições e sintomas. Estes, levando à procura de psicanálise, para em sua decomposição, gerar outras composições (sínteses) em novas formas de concertos. (PAVAN, 2005)

Mal-estar e clínica, inevitavelmente nos remete a Freud em seu conhecido texto "Mal-estar e civilização" (FREUD, 1930) fazendo pensar na infindável luta entre o indivíduo e a sociedade, as pulsões e suas vicissitudes, dentre elas a repressão, necessária, segundo Freud, para a organização social humana (Cultura).

Se a Repressão foi considerada pelo fundador da Psicanálise, a "pedra angular" sobre a qual repousa toda sua estrutura (FREUD, 1914), como manter essa visão numa Sociedade em que a Repressão é reprimida? Onde a Interdição é interditada? Onde tudo é liberado, tornando-a (a Sociedade) uma horda sem "Pai"? A sexualidade reprimida, cujo reconhecimento permitiu o surgimento da Psicanálise não está mais presente, ao menos em nosso mundo Ocidental, da forma como se apresentava na passagem do século XIX para o XX. O mundo de relações líquidas (BAUMAN, 1998, 2001) estaria substituindo a fluidez necessária para os contatos consigo mesmo e com o outro? Fluidez e plasticidade, que, junto com a continência, considera-se necessárias para o trânsito Consciente/Inconsciente.

O que temos em nossa clínica hoje? Tomando o recorte do texto acima para refletirmos, vemos que a angústia ainda está presente, sendo, como sempre foi, o motivo da procura de 
análise, denunciadora que é de conflito e ameaça ao Eu. Os sintomas também estão persentes, como podemos ver nas reações fóbicas do paciente. Também se apresentam ali as inibições e ao mesmo tempo o desejo por desenvolvimento. Não é incomum em nossa clínica de hoje a predominância das perversões (o negativo das neuroses) e também os quadros borderlines, indicativos das patologias dos limites. Podemos considerar estes, reflexos de desenvolvimentos determinados pelas características sociais da contemporaneidade?

Observa-se também como o meio acaba se refletindo em nossos divãs. Estaria o setting analítico também se liquefazendo? O que deveria ser um contraste necessário para vivencialmente observar-se o fenômeno psíquico estaria se tornando "adaptativo" ao meio (social) com os questionamentos sobre o número de sessões, valores econômicos, uso de mídias, etc.?

A Psicanálise sempre se apresentou para enfrentar Resistências (internas e externas). Estaria agora nosso baluarte tendo que se conformar com o meio? Ideologias, valores sociais, institucionais e midiáticos "invadem" o setting, e mais ou menos imperceptivelmente determinam condutas na sessão, com reflexos sobre os fins da Psicanálise. Há riscos, dentre outros, da Psicanálise caminhar na direção de psicossinteses, problema já apontado por Freud, nos aproximando de psicoterapias comportamentais?

Se a Psicanálise descoberta por Freud ficasse a serviço de qualquer demanda social, teríamos as consequências que se tornaram visíveis na história, notadamente nos Estados Unidos da América do Norte, quando ficaram "encantados" com a "peste" levada por Freud ${ }^{3}$, ao invés de desconcertados. A Psicanálise posta a serviço da Psiquiatria (durante muito tempo, não médicos lá eram proibidos de fazer formação psicanalítica em seus Institutos) e vista como meio adaptativo, esteve "em moda" por algumas décadas, fenecendo com o advento de tratamentos mais "eficazes" para debelar os sintomas pela psicofarmacologia (como previra Freud) e socialmente pelas terapias comportamentais. Esse mesmo movimento não estaria grassando entre nós? Não vemos em nosso meio médico hoje a preferência por indicação para seus pacientes de psicoterapias cognitivo-comportamentais? Isto não caracteriza, o que

\footnotetext{
3 "Eles não sabem que estamos lhes trazendo a peste" - Frase atribuída a Freud, dita a Jung quando da chegada dele aos EEUU para proferir as Conferencias na Clarke University, em 1909.
} 
podemos chamar, a "ditadura da eficiência" inerente à Tecnologia do mundo contemporâneo? (Pavan, 2005)

Estamos em desconcerto com o mundo contemporâneo, não menos que Freud no seu. Como frisou Marcio em seu trabalho, temos que nos haver com a tarefa de como mantermos a fidelidade com a tradição, sem nos tornarmos cinzas e ao mesmo tempo como nos relacionarmos com um meio cujas características estão mais voltadas para as sínteses que para as análises. Como apontou Zygmunt Bauman, Educação e imediatismo não combinam, e acredito, podemos dizer o mesmo em relação à Psicanálise.

A "infosfera" nos impregna de dados, a Tecnologia vai na direção da manipulação e domínio dos objetos para uma função de utilidade imediata. Esse mundo factual, sobrecarregado de informações, se contrasta com a essência que nos trouxe até aqui culturalmente, ou seja, nosso desenvolvimento através da criatividade numa forma poética, que se distingue da manipulação tecnológica, a qual foi gerada por este espírito criativo e não fortuitamente. É bom lembrarmos que a Tecnologia foi gerada pela criatividade humana, e não o contrário.

A Psicanálise, assim como toda Ciência, se faz impulsionada por uma visão Estética do Mundo, onde nossas relações devem ser guiadas por uma conduta baseada na Ética, para utilizando a Razão Lógica alcançarmos nossos objetivos.

Nosso desconcerto é o que move rumo a um "Concerto Social", gerando novos desconcertos. Eis o lugar da Psicanálise como disse Freud: propiciar pela análise, novas sínteses (que se fazem naturalmente) para o desenvolvimento pessoal, num fluxo dinâmico e não linear, colaborando dentro de seus limites, para possivelmente levar à evolução da Humanidade como um todo.

Que esses questionamentos possam propiciar um fecundo e proveitoso diálogo sobre nosso desconcerto, como pessoas e analistas. 
Muito obrigado!

\section{Referências}

BAUMAN, Z. (1998). O mal-estar da pós-modernidade. Rio de Janeiro: Zahar.

BAUMAN, Z. (2001). Modernidade líquida. Rio de Janeiro: Zahar.

FREUD, S. (1974). O mal-estar na civilização. (1930[1929]) in: Ed.St.Brasil. Obras Psicológicas Completas de Sigmund Freud. v. XXI. Rio de Janeiro: Imago. (Trabalho original publicado em 1930).

FREUD, S. (1974). A história do movimento psicanalítico. (1914) in: Ed.St.Brasil. Obras Psicológicas Completas de Sigmund Freud. v. XIV. Rio de Janeiro: Imago. (Trabalho original publicado em 1914).

PAVAN, J.A. A ditadura da eficiência - Psicanálise e Psicossíntese- Rev. Brasil. Psican: v.39 n.2 p.157-61, 2005. Apresentado no Congresso Brasileiro de Psicanálise, Brasília, 2005 